\title{
Analisis Skala Usaha Dan Finansial Minyak Sere Wangi (Cymbopogon nardus rendle. Lin) Di Kabupaten Gayo Lues
}

\author{
Fauzah Aziz ${ }^{1}$ \\ Indra ${ }^{2 *}$ \\ Abubakar Karim ${ }^{3}$ \\ ${ }_{1}$ Mahasiswa Program Magister Konservasi Sumberdaya Lahan, Universitas Syiah Kuala \\ 2 Program Studi Agribisnis, Universitas Syiah Kuala \\ 3Program Studi Ilmu Tanah, Universitas Syiah Kuala \\ *email: indrazainun@unsyiah.ac.id \\ Diterima: Januari 2021; Disetujui: September 2021; Dipublish: Oktober 2021
}

\begin{abstract}
Abstrak
Sere Wangi merupakan komoditas perkebunan yang menjadi primadona di Kabupaten Gayo Lues dengan produksi terbesar dibandingkan produksi komoditas lainnya. Konstribusi subsektor perkebunan terhadap perekonomian daerah juga cukup besar karena di Kabupaten Gayo Lues hingga saat ini telah banyak bergerak di bidang usaha perkebunan terutama tanaman Sere Wangi. Tujuan penelitian ini adalah menentukan skala usaha dan finansial usaha tani sere wangi yang diolah menjadi minyak sere wangi di Kabupaten Gayo Lues. Penelitian dilaksanakan di Kabupaten Gayo Lues, dengan metode deskriptif. Metode penelitan yaitu survey dengan pengambilan sampel dilakukan secara purposive sampling dengan jumlah data yang diambil Petani sebanyak 99 responden serta Pedagang sebanyak 10 responden dengan alat analisis yang digunakan adalah analisis kuantitatif. Hasil penelitian petani sere wangi sudah memperoleh keuntungan dengan ratarata produksi minyak sere wangi sebesar $164,55 \mathrm{~kg} /$ tahun, dengan luas lahan minimal diusahakan seluas 0,67 ha atau 6.657,09 $\mathrm{M}^{2}$, petani sudah BEP untuk luas lahan. Secara finansial, usahatani sere wangi layak untuk tetap dikembangan dengan nilai Net Benefit Cost Ratio (NBCR) sebesar 2,57. Artinya setiap satu rupiah yang dikeluarkan selama umur usahatani sere wangi menghasilkan Rp 2,57 satuan manfaat bersih.
\end{abstract}

Kata Kunci : Sere Wangi, Skala Usaha, Kelayakan. BEP

\begin{abstract}
Sere Wangi is a plantation commodity which is the prima donna in Gayo Lues Regency with the largest production compared to the production of other commodities. The contribution of the plantation sub-sector to the regional economy is also quite large because in Gayo Lues Regency, up to now, there have been many activities in the plantation business, especially the Sere Wangi plant. The purpose of this study was to determine the scale of business and financial business of citronella farming which is processed into citronella oil in Gayo Lues Regency. The research was conducted in Gayo Lues Regency, with a descriptive method. The research method is survey with sampling done by purposive sampling with the amount of data taken by farmers as many as 99 respondents and traders as many as 10 respondents. The research results of sere wangi farmers have obtained profits with an average production of citronella oil of $164.55 \mathrm{~kg}$ / year, with a minimum cultivated area of 0.67 ha or 6,657.09 M2, farmers have BEP for land area. Financially, sere wangi farming is feasible to continue to be developed with a Net Benefit Cost Ratio (NBCR) value of 2.57. This means that every one rupiah that is spent during the farming life of lemongrass produces $R p 2.57$ units of net benefits.
\end{abstract}

Keywords: Citronella Oil, Business Scale, Feasibility. BEP 
daun ketika dipanen, juga dipengaruhi oleh cara penanganan daun setelah panen dan penyulingan (Karim et al., 2020).

Petani sere wangi selain melakukan budidaya juga melakukan pengolahan sere wangi tersebut. Sektor industri yang berkembang di Kabupaten Gayo Lues salah satunya adalah sektor industri penyulingan Sere Wangi. Petani di gayo Lues secara umum melakukan penyulingan minyak sere dengan menggunakan alat penyulingan sederhana. Industri penyulingan Sere Wangi sebanyak 5.452 unit yang paling dominan mengangkat perekonomian masyarakat (Badan Pusat Statistik, 2018).

Menurut Juliarti et al., 2020 mutu minyak sere wangi terbaik diperoleh bila disuling dari daun segar. Dengan adanya usaha sere wangi tersebut diharapkan dapat menciptakan lapangan pekerjaan, meningkatkan pendapatan dan kesejahteraan para petani pemilik lahan dan para petani yang tidak memiliki lahan di Kabupaten Gayo Lues yang diukur dengan indikator kebutuhan hidup layak (KHL). Untuk itu perlu dilakukan kajian skala usaha dan finansial usaha minyak sere wangi di Kabupaten Gayo lues untuk dapat mengetahui luasan lahan yang diperlukan oleh petani untuk dapat memenuhi hidup layak sesuai dengan KHL di Kabupaten Gayo Lues.

\section{METODE PENELITIAN}

Penelitian dilaksanakan di Kabupaten Gayo Lues, yaitu di Kecamatan Blang Jerango, Blang Pegayon, Blangkejeren, Dabun Gelang, Kuta Panjang, Pantan Cuaca, Pining, Putri Betung, Rikit Gaib, Terangun dan Tripe Jaya yang merupana daerah dengan kesesuaian lahan (mulyana, 2019). Metode penelitian yang digunakan adalah metode deskriptif, yang merupakan suatu metode penelitian dalam meneliti data-data yang dikumpulkan, disusun, dijelaskan, serta dianalisis. Metode pengambilan sampel dilakukan secara purposive sampling dengan jumlah data yang diambil petani sebanyak 99 responden untuk kelas kesesuaian lahan dimana di setiap kecmatan diambil sampel sebanyak 9 orang petani serta pedagang sebanyak 10 responden sebagai sumber informasi tambahan untuk melihat rantai pemasaran.

Penghitungan skala usaha luas lahan dan produksi dianalisis dengan menggunakan pendekatan BEP (Break Event Point). Ada 3 pendekatan dalam menghitung BEP yaitu:

BEP volume produksi

$$
\left.=\frac{\text { Total biaya produksi }\left(\frac{R p}{k g}\right)}{\text { Harga Jual }(R p)} \ldots \ldots 1\right)
$$

BEP harga produksi

$$
\left.=\frac{\text { Total biaya produksi }\left(\frac{R p}{\mathrm{~kg}}\right)}{\text { Total produksi }(R p)} \ldots . . .2\right)
$$

BEP luas lahan

$$
\left.=\frac{\text { Volum produksi }(\mathrm{Kg})}{\text { Jumlah produksi }(\mathrm{Ha})} \ldots . .3\right)
$$


Metode penghitungan skala usaha luas lahan dan produksi dianalisis dengan menggunakan pendekatan BEP (Break Event Point), telah digunakan oleh (Indra, 2011) dalam menghitung skala usaha pada usahatani kopi arabika dan (Bagio et al., 2020) pada usahatani kelapa sawit. Untuk menghitung pendapatan usahatani (Soekartawi, 2011) dan kelayakan finansial usahatani sere wangi dapat dilakukan dengan menggunakan beberapa indikator pendekatan atau alat analisis (Kadariah, 2001) sebagai berikut :

1. Net Present Value (NPV)

$$
\left.\mathrm{NPV}=\sum_{t=0}^{n} \frac{(\mathrm{Bt}-\mathrm{Ct})}{(1+\mathrm{i}) \mathrm{t}} \ldots 4\right)
$$

Keterangan :

$\mathrm{Bt}=$ penerimaan atau benefit

tahun ke t $(\mathrm{Rp} / \mathrm{kg})$;

$\mathrm{Ct}=$ biaya atau cost pada tahun ke $\mathrm{t}$;

$\mathrm{n}=$ lamanya periode waktu;

$\mathrm{i}=$ suku bunga kredit petani pada tahun penelitian (2020).

2. Internal Rate of Return (IRR)

$\left.\operatorname{IRR}=i_{0}+\left(i_{1}-i_{0}\right) \frac{N P V}{N P V_{0}-N P V_{1}} . .5\right)$

Keterangan :

$i_{0}=$ Tingkat bunga yang berlaku di pasar modal (opportunity cost of capital);

$i_{1}=$ Tingkat bunga pembanding (discount rate pembanding);

$\mathrm{NPV}_{0}=\mathrm{NPVpada} i$

$\mathrm{NPV}_{1}=\mathrm{NPV}$ pada $i_{1}$

3. Payback Period (PP)

$P P=t+\frac{c}{b} x 1$ tahun ...6)

Dimana:

$P P=$ Payback Period $t=$ tahun terakhir dimana jumlah net cash flow kumulatif belum menutupi nilai investasi

$b=$ selisih dari nilai kumulatif net cash flow pada tahun ke-t dengan nilai investasi

$c=$ nilai net cash flow pada tahun ke- $(\mathrm{t}+1)$ atau saat PBP berada

4. Analisis Nilai Pengganti (Switching Value), Analisis switching value digunakan untuk memperhatikan dampak perubahan dari suatu variabel terhadap hasil analisis kelayakan.

\section{HASIL DAN PEMBAHASAN}

Skala ekonomi usaha tani sere wangi dapat dihitung dengan titik impas pulang pokok atau Break Event Point, baik itu BEP berdasarkan jumlah produksi minyak sere wangi, harga jual serta luas lahan minimal yang layak untuk dibudidayakan.

* BEP Berdasarkan Jumlah Produksi

$$
\begin{aligned}
B E P_{\text {Jumlah Produksi }} & \\
& =\frac{29.126 .100}{177.000} \\
& =164,55 \mathrm{~kg} / \text { tahun }
\end{aligned}
$$

Berdasarkan analisis BEP, ratarata petani sere wangi memperoleh keuntungan rata-rata produksi sere wangi sebesar $164,55 \mathrm{~kg} /$ tahun. Sedangkan rata-rata sere wangi yang diperoleh dari usahatani sere wangi pada lokasi penelitian adalah 247,19 $\mathrm{kg} /$ tahun, artinya usahatani ini sudah dapat dikatakan layak dari segi 
produksi. Hal ini disebabkan adanya kesesuaian lahan budidaya sere wangi berdasarkan penelitian Mulyana (2019) bahwasanya 50,98 persen luas lahan masuk dalam kelas cukup sesuai (S2).

* BEP Berdasarkan Harga Jual (Rp)

$$
\begin{aligned}
B E P_{\text {Harga Jual }} & =\frac{29.126 .100}{247,19} \\
& =117.830,41 \mathrm{Rp} / \mathrm{kg}
\end{aligned}
$$

Berdasarkan BEP harga jual minyak sere wangi adalah Rp. 117.830,41 per kg, sedangkan kondisi tahun 2020, harga jual minyak sere wangi rata-rata diatas Rp. 150.000 per kg. Dengan demikian harga jual dipasaran saat ini sudah layak serta petani sudah diuntungkan.

$$
\begin{aligned}
& \text { BEP Luas lahan garapan (farm size) } \\
& \text { Titik Impas Luas Lahan }=\frac{164,55}{247,19} \\
& =0,67 \mathrm{Ha}=6.657,09 \mathrm{~m}^{2}
\end{aligned}
$$

Selanjutnya untuk luas lahan yang minimal diusahakan adalah seluas 0,67 ha atau 6.657,09 $\mathrm{M}^{2}$. Artinya dengan luas lahan minimal 0,67 ha atau $6.657,09 \mathrm{M}^{2}$ petani sudah dapat memperoleh memperoleh balik modal ataupun impas antara biaya yang dikeluarkan dengan pendapatan yang diperoleh. Apabila besarnya keluarga

Tabel 1. Hasil Kelayakan Investasi Usahatani Sere Wangi Di Kabupaten Gayo Lues

\begin{tabular}{llrl}
\hline $\mathbf{N}$ & Kriteria & Indikator & $\begin{array}{c}\text { Keter } \\
\text { angan }\end{array}$ \\
\hline & Net & Rp. & \\
1 & Present & 84.815 .557 & Layak \\
& Value & 2,94 & Layak \\
2 & Net B/C & & \\
\hline
\end{tabular}

ada sebanyak 3 (tiga) orang atau jumlah tanggungan sebesar 2 (dua) orang, maka usahatani sere wangi perhektar per petani sudah dapat memenuhi kebutuhan hidup keluarga untuk menjadi keluarga sejahtera (BPS, 2019). Bila dilihat dari tingkat garis kemiskinan di Kabupaten Gayo Lues Rp. 368.583 per bulan.

Menurut (Indra, 2011) bahwa ukuran luas garapan dari suatu usahatani perlu mendapat perhatian serius agar petani tidak mengalami kerugian. Apabila total penerimaan lebih kecil dari total biaya produksi, maka usahatani tersebut rugi, dan apabila total penerimaan sama dengan total biaya produksi, maka usahatani tersebut tidak untung dan tidak rugi (pulang pokok).

Dalam menjalankan usaha tani perlu adanya analisis finansial yang bertujuan untuk melihat apakah usahatani yang akan diusahakan layak atau tidak, disini nantinya dapat mengetahui usaha ini akan mendapatkan keuntungan dan layak untuk dijalankan. Kriteria investasi yang gunakan adalah NPV, NBCR, IRR dan PBP. Berikut rekapitulasi dari hasil perhitungan kelayakan investasi usahatani sere wangi di Kabupaten Gayo Lues.

\begin{tabular}{llrl}
\hline 3 & IRR & 58,38 & Layak \\
4 & PP & 2,57 & Layak \\
& & 2 tahun 7 & \\
& \multicolumn{3}{c}{ bulan 2 hari } \\
\hline \multicolumn{3}{c}{ Sumber : Data Primer (diolah), 2020 }
\end{tabular}


Nilai dari Net Present Value (NPV), dengan Discount Factor (DF) sebesar $14 \%$ selama umur tanaman 10 tahun (2021-2030), diperoleh manfaat bersih sebesar Rp. 84.815.557. Nilai NPV > 0 artinya bahwa usaha ini sangat layak untuk dijalankan. Net Benefit Cost Ratio (NBCR) pada usahatani sere wangi yaitu 2,57. Artinya setiap satu rupiah yang dikeluarkan selama umur usahatani sere wangi menghasilkan $\mathrm{Rp}$ 2,57 satuan manfaat bersih. Dengan Nilai Net $B / C>0$ maka usahatani sere wangi layak untuk dikembangkan. Tingkat pengembalian internal proyek sebesar 58,38 persen dan nilainya jauh lebih besar dari discount factor yang berlaku yaitu 14 persen, maka usaha ini layak dan menguntungkan. Periode pengembalian biaya investasi dapat diperoleh pada saat umur tanaman mencapai 2 tahun 7 bulan 2 hari, sedangkan umur tanaman sere wangi hingga sepuluh tahun, artinya usahatani sere wangi ini layak untuk diusahakan dan dijalankan.

Sejalan dengan penelitian yang dilakukan oleh (Ernita et al., 2019) di Desa Balai Batu Sandaran Kecamatan Barangin, Kota Sawahlunto Sumatera Barat. Hasil analisis kelayakan finansial industri minyak serai wangi didapatkan NPV Rp. 1.635.698.925,IRR 37,60\%, B/C Ratio 1,45, dan PBP adalah 3 tahun 6,5 bulan. Ditinjau dari aspek ekonomi, usaha produksi minyak serai wangi dapat dikatakan layak dan menguntungkan. (Mansyur et al., 2015) secara finansial, dengan menggunakan modal Rp. 420.815 .000 usaha penyulingan minyak serai wangi ini diperoleh NPV sebesar Rp. 278.951.863, IRR sebesar 21,99\%, Net B/C sebesar 2,62, dan PBP selama 4,26 tahun. Begitu juga hasil penelitian menunjukkan bahwa Pendapatan usahatani serai wangi dengan tingkat kelayakan B/C ratio 1,75 (Sabarman, 2007). Penelitian (Farah Nabila \& Nurmalina, 2019), nilai dari NPV sebesar Rp 7.415.711.072, IRR sebesar 14,02 persen, Net B/C sebesar 1,65, dan Payback period selama 9 tahun 1 bulan. Artinya usahatani sere wangi layak untuk diusahakan.

Walaupun masih tergolong sederhana dan masih berskala kecil, proses pengolahan serai wangi menjadi minyak serai wangi layak untuk tetap dijalankan (Simatupang, T \& Ritonga, 2020), kondisi ini sesuai dengan yang ada Kabupaten Gayo Lues, proses penyulingan sere wangi masih tergolong sederhana.

Selain itu, sistem usahatani integrasi seraiwangi-ternak sapi dapat meningkatkan nilai tambah, menjamin kelestarian sumber daya alam, meningkatkan produktivitas dan pendapatan petani (Ermiati et al., 2015). Pemanfaatan limbah sere wangi juga dapat digunakan sebagai pakan ternak dan pupuk organic (Gustiar et al., 2020). Pada Desa Ceunamprong Kabupaten Aceh Jaya, sudah ada industry pangan dari bahan sere wangi yaitu Teh Serai yang sudah berjalan cukup baik dan terus mengalami peningkatan produksi 
(Usman et al., 2020). Dengan kata lain sere wangi tidak hanya diolah menjadi minyak sere wangi saja, namun dapat di olah menjadi produk yang dapat menambah pendapatan dari usahatani sere wangi tersebut.

Usahatani sere wangi yang diolah menjadi minyak sere wangi, telah menjadi salah satu pendapatan yang menompang kehidupan masyarakat setempat, dengan didukung oleh kondisi alam, habitat tumbuh tanaman sere dapat tumbuh atau hidup pada tanah - tanah marginal, serta sudah menjadi komoditi yang diusahakan turun temurun sehingga petani sudah memiliki pengalaman yang mmpuni.

Analisis sensitivitas dilakukan dari dua sisi, yaitu jika terjadi penurunan produksi sebesar 10 persen, didasarkan pada perubahan iklim dan bencana alam yang tidak dapat diperediksi dari tahun ke tahun yang dapat mempengaruhi produksi. Selanjutnya kenaikan biaya operasional usahatani sere wangi, didasarkan pada kenaikan bahan bakar minyak yang berpengaruh terhadap kenaikan saprodi yang digunakan dalam usahatani sere wangi.

Tabel 2. Analisis Sensitivitas (Penerimaan Turun 10\%) pada Usahatani Sere Wangi di Kabupaten Gayo Lues

\begin{tabular}{lrrrr}
\hline \multirow{2}{*}{ Analisis Sensitivitas } & \multicolumn{3}{c}{ Nilai pada CashFlow } \\
\cline { 2 - 5 } & $\begin{array}{c}\text { Kondisi } \\
\text { Normal } \\
\text { Awal }\end{array}$ & $\begin{array}{c}\text { Setelah } \\
\text { Perubahan }\end{array}$ & $\begin{array}{c}\text { Besar } \\
\text { Perubahan }\end{array}$ & Ket \\
\hline Penerimaan Turun 10\% & & & & \\
Net Present Value (Rp) & 84.815 .557 & 63.256 .461 & 21.559 .096 & Layak \\
Net B/C & 2,94 & 2,19 & 0,75 & Layak \\
IRR (\%) & 58,38 & 47,96 & 10,41 & Layak \\
PBP & 2,57 & 3,16 & $-0,59$ & Layak \\
\hline
\end{tabular}

Sumber : Data Primer (diolah), 2020

Perhitungkan penerimaan turun $10 \%$ dalam cashflow, NPV yang diterima selama umur proyek akan berkurang sebesar Rp. 21.559.096 menjadi Rp. 63.256.461. Tingkat pengembalian internal turun sebesar 10,41 persen menjadi 47,96 persen. Menerima manfaat bersih sebesar 3,16 artinya dari setiap satu rupiah biaya yang dikeluarkan akan menghasilkan Rp 3,16. Akan tetapi, periode pengembalian investasi bertambah panjang menjadi 3 tahun 2 bulan 5 hari. Jika terjadi kenaikan biaya opersional sebesar $10 \%$, maka NPV yang akan diterima selama umur proyek akan berkurang sebesar Rp 10.194.040 dari NPV awal yaitu sebesar Rp. 74.621.517. Sedangkan tingkat pengembalian internal turun sebesar 5,38 persen menjadi 53,00 persen. 
Tabel 3. Analisis Sensitivitas (Biaya Operasional Naik 10\%) pada Usahatani Sere Wangi di Kabupaten Gayo Lues

\begin{tabular}{lrrrr}
\hline & \multicolumn{3}{c}{ Nilai pada CashFlow } \\
\cline { 2 - 5 } \multicolumn{1}{c}{ Analisis Sensitivitas } & $\begin{array}{c}\text { Kondisi } \\
\text { Normal } \\
\text { Awal }\end{array}$ & $\begin{array}{c}\text { Setelah } \\
\text { Perubahan }\end{array}$ & $\begin{array}{c}\text { Besar } \\
\text { Perubahan }\end{array}$ & Ket \\
\hline Biaya Operasional Naik 10\% & & & & \\
Net Present Value (Rp) & 84.815 .557 & 74.621 .517 & 10.194 .040 & Layak \\
Net B/C & 2,94 & 2,59 & 0,35 & Layak \\
IRR (\%) & 58,38 & 53,00 & 5,38 & Layak \\
PBP & 2,57 & 2,86 & $-0,29$ & Layak \\
\hline
\end{tabular}

Sumber : Data Primer (diolah), 2020

Menerima manfaat bersih sebesar 1,95 artinya dari setiap satu rupiah biaya yang dikeluarkan akan menghasilkan Rp 2,95. Akan tetapi, periode pengembalian investasi bertambah panjang menjadi 3 tahun 3 bulan 11 hari. Berdasarkan hasil perhitungan analisis sensitivitas usahatani sere wangi masih layak untuk diusahakan dan dilanjutkan.

\section{SIMPULAN}

Rata-rata petani sere wangi sudah memperoleh keuntungan dengan rata-rata produksi minyak sere wangi sebesar 164,55 kg/tahun, dengan luas lahan minimal diusahakan seluas 0,67 ha atau $6.657,09 \mathrm{~m}^{2}$. Secara finansial, usahatani sere wangi layak untuk tetap dikembangan dengan nilai $\mathrm{Net}$ Benefit Cost Ratio (NBCR) sebesar 2,57 . Artinya setiap satu rupiah yang dikeluarkan selama umur usahatani sere wangi menghasilkan $\mathrm{Rp}$ 2,57 satuan manfaat bersih.

\section{DAFTAR PUSTAKA}

Anwar, K., \& Sartika, S. (2020). Pengaruh Luas Lahan Dan Modal Terhadap Pendapatan Petani Serai Wangi Di Desa Ujung Kecamatan Kuta Panjang Kabupaten Gayo Lues. Jurnal
Ekonomi Pertanian Unimal, 03(02), 9-16. url: http://ojs.unimal.ac.id/index.php/J EPU

Badan Pusat Statistik. (2018). Kabupaten Gayo Lues dalam Angka 2018. BPS Kabupaten Gayo Lues.

Bagio, B., Handayani, S., Nasution, A., \& Zulkarnain, Z. (2020). Analisis Pendapatan Usahatani Kelapa Sawit Di Trans Bakal Buah Kota Subulussalam. Ekombis, 6(2), 158164.

https://doi.org/10.35308/ekombis. v6i2.2880

Daswir. (2010). Peran Seraiwangi Sebagai Tanaman Konservasi Pada Pertanaman Kakao Di Lahan Kritis. Bul. Littro. Vol. 21 No. 2, 2010, 117 128 PERAN, 2(2), 117-128.

Ermiati, E., Pribadi, Rini, E., \& Wahyudi, A. (2015). Pengkajian Usahatani Integrasi Seraiwangi-Ternak Sapi. 26.

Ernita, Y., Novita, Sri, N., Jamaluddin, Indra, L., \& Rildiwan. (2019). Analisis Nilai Tambah Dan Kelayakan Finansial Industri Minyak Serai Wangi. Journal of Aplied Agricultural Science and Technology, 3(1), 91-104. https://doi.org/https://doi.org/10. 32530/jaast.v3i1.79

Farah Nabila, W., \& Nurmalina, R. (2019). Analisis Kelayakan Usaha Minyak Serai Wangi Pada Kondisi Risiko (Studi Kasus Pt. Musim Panen Harmonis). Forum Agribisnis, 9(2), 
143-159.

https://doi.org/10.29244/fagb.9.2. 143-159

Gustiar, F., Munandar, M., Negara, Z. P., \& Efriandi, E. (2020). Pemanfaatan Limbah Serai Wangi Sebagai Pakan Ternak dan Pupuk Organik di Desa Payakabung, Kabupaten Ogan Ilir, Sumatera Selatan. Abdihaz: Jurnal Ilmiah Pengabdian Pada Masyarakat, 2(1), 16. https://doi.org/10.32663/abdihaz. v2i1.1114

Indra. (2011). Penentuan Skala Usaha Dan Analisis Efisiensi Ekonomi Usahatani Kopi Rakyat Di Kabupaten Aceh Tengah. Jurnal Agrisep, 12(1), 15-22.

https://doi.org/10.24815/agrisep.v $12 \mathrm{i} 1.206$

Juliarti, A., Wijayanto, N., Mansur, I., \& Trikoesoemaningtyas. (2020). Analisis Rendemen Minyak Serehwangi (Cymbopogon nardus L.) yang Ditanam dengan Pola Agroforestri dan Monokultur pada Lahan Revegetasi Pasca Tambang Batubara (Citronella (Cymbopogon nardus L.) Oil Yield Analysis Planted with Agroforestry and Monoculture Pa. Jurnal Sylva Lestari, 8(2), 181188.

Kadariah. (2001). Evaluasi Proyek Analisis Ekonomi. Lembaga Penelitian Fakultas Ekonomi UI.

Karim, A., Sugianto, S., Fazlina, Y. D., Rusdi, M., Manfarizah, M., \& Hifnalisa, H. (2020). Land Arrangement for Citronella (Cymbopogon Nardus) and Arabica Coffee in the Cultivation Area in Gayo Lues District, Aceh Province Indonesia: A Land Suitability Approach. Aceh International Journal of Science and Technology, 9(3), 207-215. https://doi.org/10.13170/aijst.9.3.
18495

Mansyur, M., Màruf, A., \& Ashadi, R. W. (2015). Studi Kelayakan Usaha Penyulingan Minyak Serai Wangi (Citronella Oil) di Lembang Bandung Veasibility Study on Establishment Lemongrass Oil Extraction in Lembang Bandung. Jurnal Pertanian, 6(1), 15-20. https://ojs.unida.ac.id/jp/article/vi ew $/ 40$

Mulyana, dkk. 2019. Analisis Kesesuaian Lahan Untuk Pengembangan Tanaman Sere Wangi di Kabupaten Gayo Lues. Jurnal Ilmiah Mahasiswa Pertanian Vol. 4 No. 1 Februari 2019 Sabarman, D. (2007). Analisis Ekonomi Usahatani Serai Wangi (Studi Kasus Kecamatan Gunung Halu, Kabupaten Bandung Selatan). Bul. Littro. Vol. XVIII No. 2, 2007, 203 - 221, 18(2), 203-221.

Simatupang, T, J., \& Ritonga, R. (2020). Analisis nilai tambah pengolahan serai wangi menjadi minyak serai wangi dan pemasarannya. 4(1), 161166.

Soekartawi. (2011). Ilmu Usaha Tani. Universitas Indonesia.

Suryani, E., \& Nurmansyah, N. (2013). Penampilan Beberapa Klon Unggul Serai Wangi Pada Dua Agroekologi Berbeda Di Sumatera Barat. Buletin Penelitian Tanaman Rempah Dan Obat, 24(2), 73-78. https://doi.org/10.21082/bullittro. v24n2.2013.\%p

Usman, M., Amru, T., Arida, A., \& Bagio, B. (2020). Analisis Pendapatan Dan Kelayakan Usaha Produksi The Serai Pada Bumg Desa Ceunamprong Kecamatan Indra Jaya Kabupaten Aceh Jaya. Ekombis, 6(2), 179-188. https://doi.org/https://doi.org/10. 35308/ekombis.v6i2.2882 